\title{
Nail bed defect reconstruction using a thenar fascial flap and subsequent nail bed grafting
}

\author{
Kyung Jin Lee, Yong Woo Kim, Jin Soo Kim, Si Young Roh, Dong Chul Lee \\ Department of Plastic and Reconstructive Surgery, Gwangmyeong Sungae General Hospital, Gwangmyeong, Korea
}

\begin{abstract}
Background Full-thickness nail bed defects with significant exposure of the distal phalanx are typically challenging to reconstruct. We describe a novel method of nail bed defect reconstruction using a thenar fascial flap combined with nail bed grafting.

Methods Full-thickness nail bed defects were reconstructed in a 2-stage operation involving the placement of a thenar fascial flap and subsequent nail bed grafting. A proximally-based skin flap was designed on the thenar eminence. The flap was elevated distally to proximally, and the fascial layer covering the thenar muscle was dissected proximally to distally. The skin flap was then closed and the dissected fascial flap was turned over (proximal to distal) and inset onto the defect. The finger was immobilized for 2 weeks, and the flap was dressed with wet and ointment dressings. After 2 weeks, the flap was divided and covered with a split-thickness nail bed graft from the great toe. Subsequent nail growth was evaluated on follow-up.

Results Nine patients (9 fingers) treated with the novel procedure were evaluated at followup examinations. Complete flap survival was noted in all cases, and all nail bed grafts took successfully. Five outcomes (55.6\%) were graded as excellent, three (33.3\%) as very good, and one $(11.1 \%)$ as fair. No donor site morbidities of the thenar area or great toe were observed. Conclusions When used in combination with a nail bed graft, the thenar fascial flap provides an excellent means of nail bed reconstruction.
\end{abstract}

Keywords Finger injuries / Nails / Fascia / Reconstructive surgical procedures / Surgical flaps
Correspondence: Dong Chul Lee Department of Plastic and Reconstructive Surgery, Gwangmyeong Sungae General Hospital, 36 Digital-ro, Gwangmyeong 14241, Korea

Tel: +82-2-2680-7238

Fax: +82-2-2615-7218

E-mail: ophand@gmail.com

This article was presented at the 74th Congress of the Korean Society of Plastic and Reconstructive Surgeons on November 17, 2016, in Seoul, Korea.

\section{INTRODUCTION}

Full-thickness nail bed defects with significant exposure of the distal phalanx are typically challenging to reconstruct because of the absence of a vascularized wound bed for the graft to take. Because of the proximity of the bone and nail bed, exposure of the distal phalanx is common in nail injuries. Exposed bone can rapidly desiccate, and scarring on the nail bed can lead to nail deformity. The sterile matrix is a unique structure that is challenging to substitute because it is a thin and highly vascularized tissue. To better mimic the properties of the sterile matrix, we used the fascia of the thenar muscle, obtained by extending the fascial layer of a conventional thenar flap. Herein, we describe a new, 2-stage method for reconstructing nail bed defects using this thenar fascial flap, followed by nail bed grafting.

\section{METHODS}

This retrospective study was approved by Gwangmyeong Sungae Hospital's Ethics Review Board (IRB No. KIRB-2017-N- 
006), and all patients provided informed consent for undergoing the procedures. Between May 2014 and August 2016, we selected patients who presented to our department with a fullthickness nail bed defect and significant exposure of the distal phalanx. All patients were treated via a 2 -stage surgical procedure that involved first covering the exposed distal phalanx with a thenar fascial flap, followed by 2 weeks of immobilization and then flap division with nail bed grafting. Because this procedure is suitable for treating injuries to the index, middle, and ring fingers, we excluded patients with injuries to the thumb or little finger. We also excluded patients with a contaminated or infected wound, or with bone necrosis of the distal phalanx.

\section{Surgical technique}

The procedure can be performed under regional or general anesthesia. All patients included in the study had full-thickness nail bed defects with distal phalanx exposure, with a defect size that exceeded half the size of the sterile matrix (Fig. 1A). We designed a proximally based skin flap on the thenar eminence [1], and made an $\mathrm{H}$ - or $\mathrm{U}$-shaped skin incision. The radial margin of the flap was parallel to the skin crease of the first metacarpophalangeal joint [2]. The skin flap was elevated distally to proximally on the suprafascial level, and the fascial layer covering the thenar muscle was dissected proximally to distally, opposite to the skin flap, taking particular care not to injure the radial digital nerve of the thumb [2]. To reduce tension between the flap and the recipient finger, the fascial flap was designed to be $30 \%$ larger than the defect (Fig. 1B). The skin flap was then closed and the dissected fascial layer was turned over (proximal to distal) and inset onto the defect using 5-0 nylon (Fig. 1C). When we accidentally found a perforating artery entering the fascia, we saved it in order to promote blood circulation to the fascial flap; we also changed the direction of flap attachment to the finger in order to avoid violating the integrity of this perforator.

In cases 1, 4, 5, and 9, the skin and subcutaneous tissue were also carried over to cover partial defects of the fingertip. To bring the recipient finger closer to the donor site, the thumb was palmar-abducted and the recipient finger was flexed at the metacarpophalangeal joint and the proximal interphalangeal joint.

Wet and ointment dressings with immobilization were applied for 2 weeks. Afterwards, the flap was divided and split-thickness nail bed grafting was performed. Under a digital tourniquet with digital block of the great toe, the nail plate was removed and the nail bed graft was designed. The split-thickness sterile matrix was harvested with a razor blade, using a free-hand technique under loupe magnification (Fig. 1D). The razor blade was inserted into the lateral or medial border of the designed sterile matrix and advanced towards the opposite direction. We adjusted the cutting depth to a level at which the blade was visible through the graft, which ensured that the harvested graft had appropriate thickness [3]. Following trephination to prevent subungual hematoma, the nail plate was reinserted into the eponychial fold of the great toe. The graft was placed over the fascial flap and fixed with 6-0 black silk. Vaseline gauze strip dressing was applied for light compression, and the thenar area was closed primarily. Active exercise began 3 days after the operation

\section{Fig. 1. Nail bed defect reconstruction technique (case 2)}

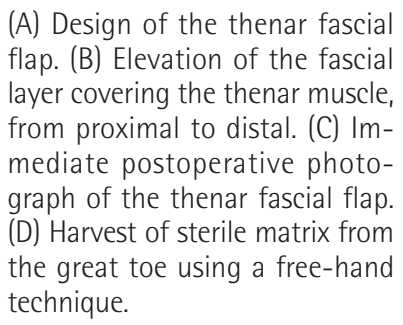

(A) Design of the thenar fascial flap. (B) Elevation of the fascial layer covering the thenar muscle, from proximal to distal. (C) Immediate postoperative photograph of the thenar fascial flap. (D) Harvest of sterile matrix from the great toe using a free-hand technique.
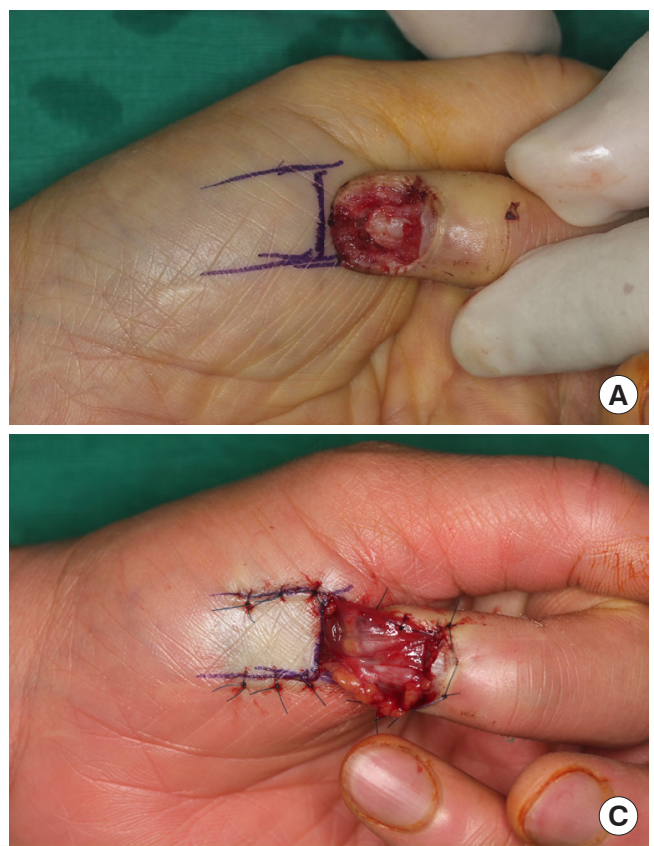
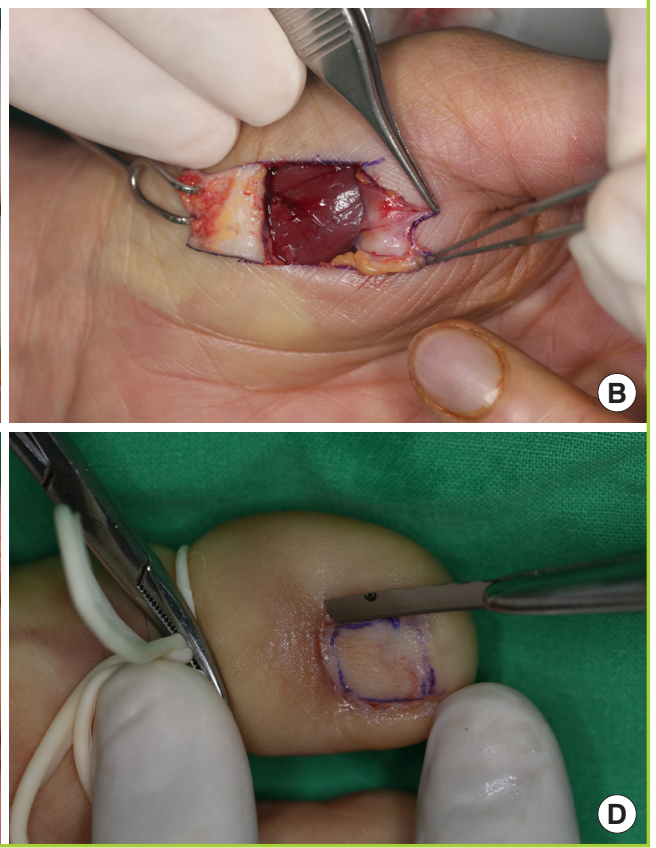
and the dressing was removed at 5 days postoperatively. Routine changes of the ointment dressing were performed. Subsequent nail growth was evaluated on follow-up.

\section{Evaluation of outcomes}

Nail growth was evaluated by retrospective review of the clinical charts and photographs taken during follow-up. At the final follow-up, the nails were evaluated by comparing them with the corresponding contralateral nails. The outcomes were evaluated as follows. Each instance of nail deformity was evaluated as major or minor, and the final outcome was graded based on the total number of major and minor variations as excellent, very good, good, fair, or poor (Table 1), according to Zook's criteria (Table 2) [4].

\section{RESULTS}

Nine patients (age range, 25-72 years; mean age, 44 years; 7 males and 2 females; 9 fingers) were evaluated at follow-up examinations. Of the nine fingers treated ( 3 index fingers, 3 ring fingers, and 3 middle fingers), seven were on the left hand, and two on the right hand.

The mechanisms of nail bed injury were as follows: jamming in a door ( 1 finger), crushing in a machine ( 5 fingers), crushing between pipes ( 1 finger), grinder accident ( 1 finger), and rotary blade accident ( 1 finger). In seven patients, placement of the thenar fascial flap was performed as an initial operation within 6 days of the injury; in the remaining two patients, flap placement was performed as secondary reconstruction to cover a nail bed defect that resulted from necrosis of the replanted finger. In five cases, tuft fractures were present (55.6\%). Final follow-up examinations were performed at 6 to 26 months (average, 15 months) after surgery.

All flaps showed complete survival, without adverse events. All nail bed grafts took successfully. At 3 weeks after surgery, all patients were able to ambulate without substantial toe pain or bleeding. Nail growth was observed at an average of 4 months after surgery in both the treated finger and the donor toe.

Outcomes were excellent in five patients $(55.6 \%)$, very good in three patients (33.3\%), and fair in one patient (11.1\%) (Table 1). All nail bed reconstructions were completed by the 2 -stage

\section{Table 2. Evaluation of nail bed deformities according to} Zook's criteria [4]

\begin{tabular}{|lll|}
\hline Grade & Category & \multicolumn{1}{c|}{ Variation } \\
\hline A & Excellent & 0 \\
B & Very good & 1 Minor \\
C & Good & 2 Minor \\
D & Fair & 3 Minor or 1 major \\
E & Poor & $>3$ Minor or $>1$ major \\
\hline
\end{tabular}

\section{Table 1. Long-term outcomes of nail bed defect reconstruction using a thenar fascial flap and subsequent nail bed grafting}

\begin{tabular}{|c|c|c|c|c|c|c|c|c|c|c|c|}
\hline & \multirow{2}{*}{ Variable } & & \multicolumn{9}{|c|}{ Case } \\
\hline & & & 1 & 2 & 3 & 4 & 5 & 6 & 7 & 8 & 9 \\
\hline Nail shape & $\begin{array}{l}\text { Identical } \\
\text { Shorter } \\
\text { Narrower } \\
\text { Longitudinal curve } \\
\text { Transverse curve }\end{array}$ & $\begin{array}{l}\text { Minor } \\
\text { Minor } \\
\text { Minor } \\
\text { Minor }\end{array}$ & $\bullet$ & $\bullet$ & $\bullet$ & $\bullet$ & $\bullet$ & $\bullet$ & • & $\bullet$ & $\bullet$ \\
\hline Nail adherence & $\begin{array}{l}\text { Complete } \\
\geq 2 / 3 \\
<2 / 3\end{array}$ & $\begin{array}{l}\text { Minor } \\
\text { Major }\end{array}$ & $\bullet$ & $\bullet$ & $\bullet$ & $\bullet$ & $\bullet$ & $\bullet$ & • & $\bullet$ & $\bullet$ \\
\hline Eponychium & $\begin{array}{l}\text { Identical } \\
\text { Notched } \\
\text { Synechia }\end{array}$ & $\begin{array}{l}\text { Minor } \\
\text { Minor }\end{array}$ & $\bullet$ & $\bullet$ & $\bullet$ & $\bullet$ & - & - & $\bullet$ & $\bullet$ & $\bullet$ \\
\hline Nail surface & $\begin{array}{l}\text { Identical } \\
\text { Slightly rough } \\
\text { Very rough } \\
\text { Longitudinal ribs } \\
\text { Transverse grooves }\end{array}$ & $\begin{array}{l}\text { Minor } \\
\text { Major } \\
\text { Minor } \\
\text { Minor }\end{array}$ & $\bullet$ & $\bullet$ & $\bullet$ & $\bullet$ & $\bullet$ & - & • & $\bullet$ & $\bullet$ \\
\hline Split & $\begin{array}{l}\text { Absent } \\
\text { Present }\end{array}$ & Major & $\bullet$ & $\bullet$ & $\bullet$ & $\bullet$ & $\bullet$ & $\bullet$ & • & $\bullet$ & $\bullet$ \\
\hline Total & & $\begin{array}{l}\text { Major } \\
\text { Minor }\end{array}$ & $\begin{array}{l}0 \\
1\end{array}$ & $\begin{array}{l}0 \\
0\end{array}$ & $\begin{array}{l}0 \\
0\end{array}$ & $\begin{array}{l}0 \\
0\end{array}$ & $\begin{array}{l}0 \\
1\end{array}$ & $\begin{array}{l}0 \\
0\end{array}$ & $\begin{array}{l}0 \\
3\end{array}$ & $\begin{array}{l}0 \\
0\end{array}$ & $\begin{array}{l}0 \\
1\end{array}$ \\
\hline Grade & & & B & A & A & A & B & A & D & A & B \\
\hline
\end{tabular}




\section{Fig. 2. Healing of the donor sites}

(A) Donor site of the thenar fascial flap at 4 months postoperatively (case 2). (B) Donor site of the nail bed graft at 9 months postoperatively (case 1).
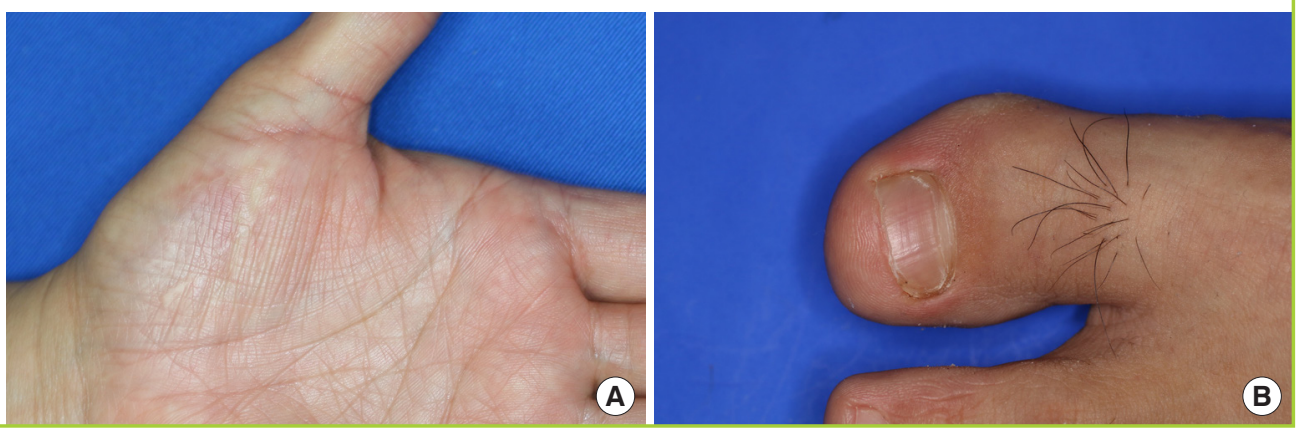

Fig. 3. Very good outcomes in case 1

(A) Following complete amputation, the finger underwent replantation. (B) At 3 weeks after replantation, the entire sterile matrix was debrided. (C) Intraoperative photograph depicting the placement of a thenar fascial flap. (D) Photograph taken at 9 months postoperatively. This result was graded as "very good" because of the presence of a mild transverse groove.
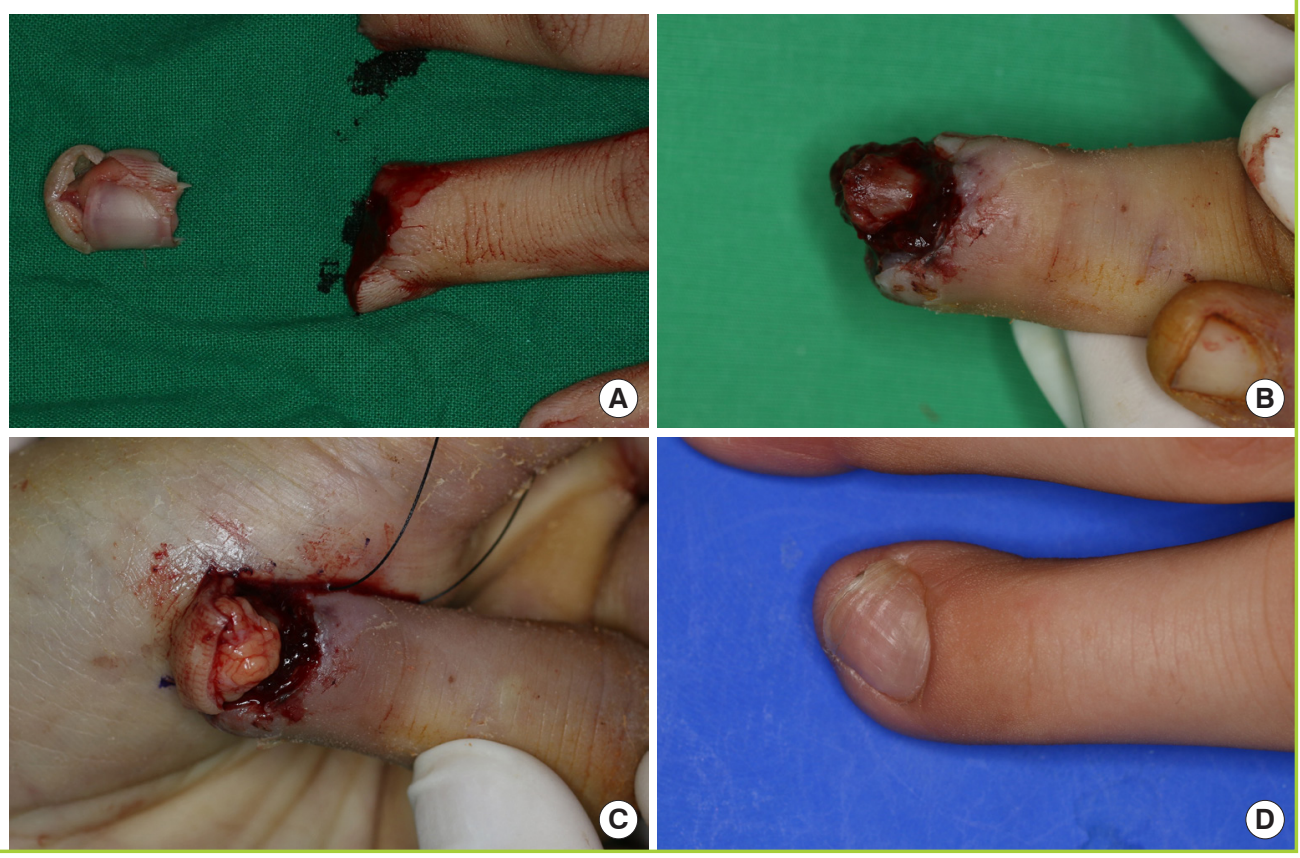

surgical procedure described above, except for case 7, where additional nailplasty was performed at 5 months postoperatively because scarring of the nail bed had caused an ingrown nail. No donor site morbidities of the thenar area or great toe were observed (Fig. 2). We further briefly describe two representative cases.

\section{Case 1}

A 25-year-old man was involved in a cutting machine accident, resulting in complete amputation of his left middle and ring fingers at the base of the distal phalanx and at the shaft of the distal phalanx, respectively. The stumps of both affected fingers were severely crushed. Both fingers were replanted. At 3 weeks postreplantation, the middle finger had survived but the nail bed of the ring finger had necrotized. After removing the necrotic sterile matrix, we found the distal phalanx bone to be viable, so we covered it with a thenar fascial flap. In this particular case, skin and subcutaneous tissue were also carried over to cover a fingertip defect. Two weeks later, the flap was divided and nail bed grafting was performed. At the 9-month follow-up, one minor variation of the transverse groove was observed, and the new nail was graded as "very good" (Fig. 3).

\section{Case 2}

A 50-year-old woman was involved in a press machine accident resulting in a crush injury to her left index finger. Almost the entire sterile matrix was lost. A thenar fascial flap was applied, and subsequent nail bed grafting was performed. At the 20-month follow-up, the new nail was graded as "excellent" (Fig. 4).

\section{DISCUSSION}

Because of their prominence at the fingertips, fingernails are the most frequent sites of hand injury. However, there are limited 


\section{Fig. 4. Excellent outcomes in case 2}

The nail bed was treated by reconstruction with a thenar fascial flap and subsequent nail bed grafting. (A) Preoperative photograph. (B) Postoperative photograph after division and nail bed grafting. (C) Photograph taken at 5 days postoperatively, after removal of the compressive dressing. (D) Photograph taken at 20 months postoperatively.
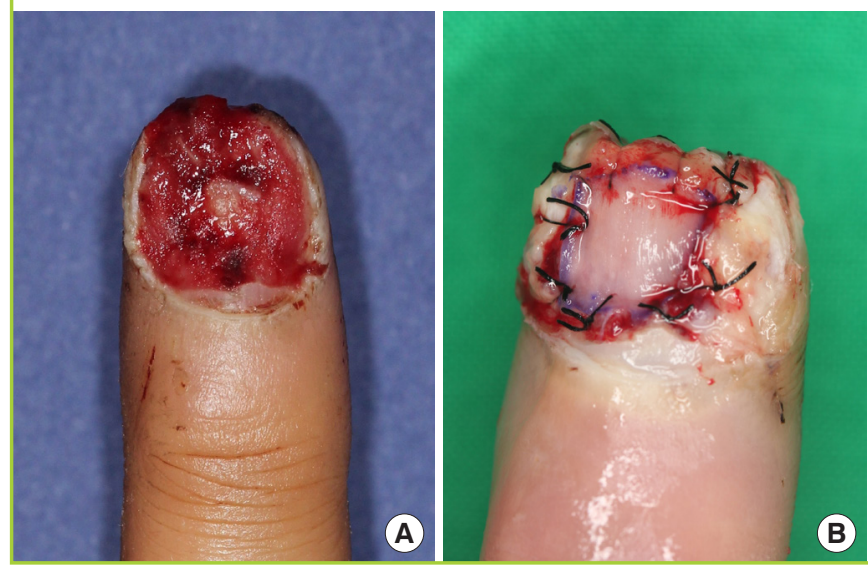

options for reconstructing defects involving near-total loss of the sterile matrix. The optimal management of nail bed defects remains controversial. In injuries involving partial loss, it is possible to advance the sterile matrix, to perform revision amputation of the fingertip, or to cover the defect with dermal or reverse dermal grafts [5]; sometimes, secondary healing is advisable. However, injuries with a full-thickness sterile matrix defect with significant exposure of the distal phalanx require other approaches. Composite nail transfer, introduced by Sheehan in 1929 [6], often fails or results in significant nail deformities [7]. While microvascular transfer of the toenail would likely yield good outcomes $[8,9]$, there are important limitations regarding the size of the nail, functional and aesthetic problems of the donor site, and technical hurdles specific to microsurgery [10]. It is therefore not easy to choose an adequate method for reconstructing the sterile matrix.

The nail bed is a smooth, flat, thin, tissue with rich blood supply that consists of the germinal matrix (proximally) and the sterile matrix (distally). The germinal matrix produces about $90 \%$ of the nail [11], whereas the sterile matrix adds a thin layer of cells to the nail undersurface, keeping the nail adherent to the nail bed [12-14]. Therefore, scarring of the germinal matrix leads to nail absence, whereas injury of the sterile matrix leads to nail deformities [4]. Fortunately, distal defects are more common than defects of the germinal matrix, which is better protected by its proximal location and the presence of the eponychium [15]. Covering nail bed defects with conventional skin grafts or flaps may produce non-adherent nail growth because the features of such grafts or flaps are not compatible with those of the sterile matrix $[16,17]$. A thenar fascial flap can effectively cover the exposed bone and provides a well-circulated thin flap
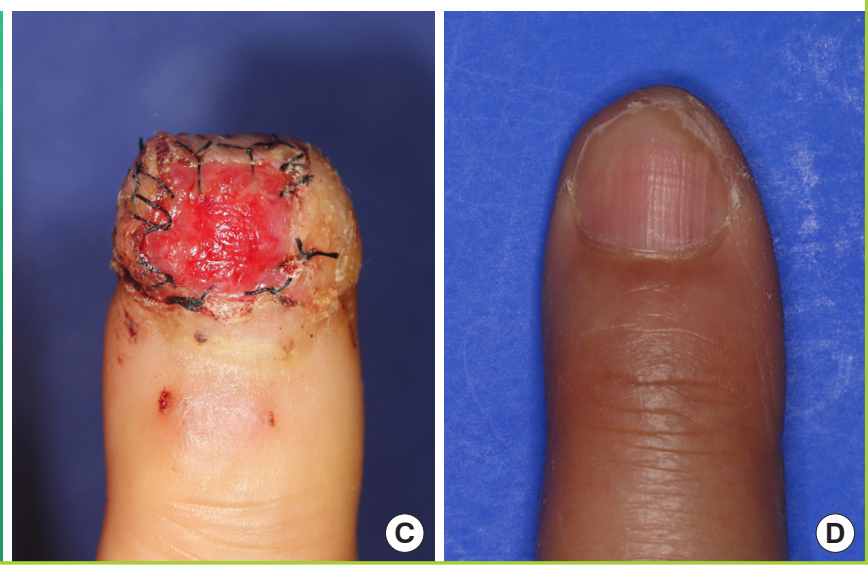

to serve as a nourishing bed for the nail bed graft. Furthermore, compared with microsurgical techniques, the proposed procedure is relatively straightforward.

However, the thenar fascial flap has its limitations. First, its indication is confined to index, middle, and ring finger injuries because the thumb tip cannot approach the thenar eminence and the tip of the little finger is anatomically distant from the thenar eminence. Second, other options, such as vascularized nail bed transfer, must be considered for germinal matrix injuries, because the thenar fascial flap cannot replace the nail-producing function of the germinal matrix. Third, the 2 weeks of immobilization required after flap placement might increase the risk of flexion contracture of the recipient finger's proximal interphalangeal joint. This risk can be minimized by cautious flap design (to reduce the flexion load on the proximal interphalangeal joint) and early active exercise after flap division [18]. Consideration should also be given to potential deviation of the distal phalanx, as was observed in case 1 . In this patient, the K-wire inserted during the initial replantation operation had to be removed during flap insetting, even though distal phalanx union had not been achieved, to avoid disturbing the blood supply to a weak and pliable fascial flap. This resulted in radial angulation of the distal phalanx because the radial-sided donor site pulled the recipient finger radially (Fig. 3C and D).

A significant limitation of the present study is the relatively small sample size. However, this study has several strengths. First, we propose a novel method of nail reconstruction that has not been reported before. Furthermore, in most cases, functional and aesthetic outcomes were excellent, and all patients were satisfied. Further study is warranted to confirm the safety and success of the proposed procedure in a large sample of patients. 
The thenar fascial flap provides multiple advantages over the use of traditional flaps, including minimal donor site morbidities, maximal support for the graft, and outstanding functional and aesthetic outcomes. When used in combination with a nail bed graft, this procedure provides an excellent means of nail bed reconstruction of full-thickness nail bed defects with distal phalanx exposure.

\section{NOTES}

\section{Conflict of interest}

No potential conflict of interest relevant to this article was reported.

\section{Ethical approval}

The study was approved by the Institutional Review Board of Gwangmyeong Sungae Hospital (IRB No. KIRB-2017-N-006) and performed in accordance with the principles of the Declaration of Helsinki. Written informed consents were obtained.

\section{Patient consent}

The patients provided written informed consent for the publication and the use of their images.

\section{ORCID}

Kyung Jin Lee https://orcid.org/0000-0002-9448-8291

Yong Woo Kim https://orcid.org/0000-0002-8834-8487

Jin Soo Kim https://orcid.org/0000-0003-3369-2974

Si Young Roh https://orcid.org/0000-0002-8625-6124

Dong Chul Lee https://orcid.org/0000-0003-4211-6901

\section{REFERENCES}

1. Dellon AL. The proximal inset thenar flap for fingertip reconstruction. Plast Reconstr Surg 1983;72:698-704.

2. Flatt AE. The thenar flap. J Bone Joint Surg Br 1957;39B:80-5.

3. Sommer NZ. Perionychium. In: Wolfe SW, Hotchkiss RN, Pederson WC, editors. Green's operative hand surgery. 7th ed. Philadelphia: Elsevier; 2016. p. 318-37.
4. Zook EG, Guy RJ, Russell RC. A study of nail bed injuries: causes, treatment, and prognosis. J Hand Surg Am 1984;9: 247-52.

5. Clayburgh RH, Wood MB, Cooney WP 3rd. Nail bed repair and reconstruction by reverse dermal grafts. J Hand Surg Am 1983;8(5 Pt 1):594-8.

6. Sheehan JE. Replacement of thumb nail. JAMA 1929;92: 1253-5.

7. Lille S, Brown RE, Zook EE, et al. Free nonvascularized composite nail grafts: an institutional experience. Plast Reconstr Surg 2000;105:2412-5.

8. Nam SB. The perionychium. In: The Korean Society for Surgery of the Hand, editors. Surgery of the hand. 1st ed. Seoul: Bumoon Education; 2014. p. 155-61.

9. Endo T, Nakayama Y. Microtransfers for nail and fingertip replacement. Hand Clin 2002;18:615-22.

10. Koshima I, Inagawa K, Urushibara K, et al. Fingertip reconstructions using partial-toe transfers. Plast Reconstr Surg 2000;105:1666-74.

11. Lewis BL. Microscopic studies of fetal and mature nail and surrounding soft tissue. AMA Arch Derm Syphilol 1954;70: 733-47.

12. De Berker D, Mawhinney B, Sviland L. Quantification of regional matrix nail production. Br J Dermatol 1996; 134: 1083-6.

13. Barron JN. The structure and function of the skin of the hand. Hand 1970;2:93-6.

14. Johnson M, Shuster S. Continuous formation of nail along the bed. Br J Dermatol 1993;128:277-80.

15. Lorea P. Primary care of nail traumas. Chir Main 2013;32: 129-35.

16. Brown RE, Zook EG, Russell RC. Fingertip reconstruction with flaps and nail bed grafts. J Hand Surg Am 1999;24:34551.

17. Shepard GH. Treatment of nail bed avulsions with splitthickness nail bed grafts. J Hand Surg Am 1983;8:49-54.

18. Melone CP Jr, Beasley RW, Carstens JH Jr. The thenar flap: an analysis of its use in 150 cases. J Hand Surg Am 1982;7: 291-7. 